\title{
(t)
}

\section{A IDEOLOGIA DA MODERNIZAÇÃO TRABALHISTA NA FORMAÇÃO SOCIAL BRASILEIRA}

\author{
The ideology of labor modernization in brazilian social formation
}

\author{
Ricardo Lara* \\ https://orcid.org/0000-0003-1631-8227 \\ Pablo Ramon Diogo** \\ https://orcid.org/0000-0001-6493-0344
}

\section{RESUMO}

O artigo objetiva analisar a ideologia da modernização trabalhista e estabelecer mediações com a formação social brasileira. Primeiramente aborda-se a sociedade de classes no capitalismo dependente e destaca-se como na formação social do Brasil o Estado torna-se o instrumento por excelência das classes dominantes para decidir os rumos das modernizações. Em seguida apresentam-se as intervenções da Confederação Nacional da Indústria (CNI) e da Federação das Indústrias do Estado de São Paulo (FIESP) na elaboração e aprovação da Lei $n^{\circ} 13.467$, de 13 de julho de 2017. Entretanto, a análise deste artigo não se restringe aos efeitos da contrarreforma trabalhista, mas principalmente às causas ideológicas que orientam as modernizações no Brasil.

\section{PALAVRAS-CHAVE}

Ideologia; Modernização trabalhista; Formação social brasileira.

\section{ABSTRACT}

We have as objective search for the ideology of labor modernization and establish mediations with the brazilian social formation. First, we approach class society in dependent capitalism and highlight how in our social formation the State becomes the instrument par excellence of the dominant classes to decide the direction of modernizations / counter-reforms. Then we analyze the interventions of the National Confederation of Industry (CNI) and Federation of Industries of the State of São Paulo (FIESP) and their main ideologues in the elaboration and approval of Law No. 13.467, of July 13, 2017. Therefore, our exposition is not limited to the effects of the labor counter-reform, but mainly the ideological causes that guide modernizations in dependent capitalism.

\footnotetext{
* Assistente Social. Doutor em Serviço Social. Professor Associado do curso de Serviço Social da Universidade Federal de Santa Catarina. (UFSC, Florianópolis, Brasil). R. Eng. Agronômico Andrei Cristian Ferreira, s/n, Trindade, Florianópolis (SC), CEP.: 88040-900. E-mail: ricardolarauf@gmail.com.

** Graduando em Serviço Social pela Universidade Federal de Santa Catarina. (UFSC, Florianópolis, Brasil). R. Eng. Agronômico Andrei Cristian Ferreira, s/n, Trindade, Florianópolis (SC), CEP.: 88040-900. E-mail: pablo.rdiogo@gmail.com.
}

DOI 10.22422/temporalis.2020v2on40p165-181 Commons Atribuição 4.0 Internacional (https://creativecommons.org/licenses/by/4.0/deed.pt_BR), que permite copiar e redistribuir o material em qualquer suporte ou formato, bem como adaptar, transformar e criar a partir deste material para qualquer fim, mesmo que comercial. O licenciante não pode revogar estes direitos desde que você respeite os termos da licença. 
KEYWORDS

Ideology; Labor modernization; Brazilian social formation.

Submetido em: 15/7/2020.

Aceito em: 19/10/2020.

\section{INTRODUÇÃO}

$\mathrm{N}$

este artigo analisamos a ideologia da modernização trabalhista e procuramos estabelecer mediações com a formação social brasileira, principalmente diante da atual conjuntura de continua e acelerada retirada de direitos sociais.

Nas sociedades de classes as ideologias encontram suas diferentes formas de expressão e operacionalização na vida social. Por isso que é errôneo entender ideologia "como formação arbitrária do pensamento de pessoas singulares” (LUKÁCS, 2013, p. 464). Em princípio, ela pode vir ao mundo pelo sujeito singular, mas é resultado das relações sóciohistóricas em que o indivíduo está inserido e, na sociedade de classes sociais antagônicas, a ideologia também se manifesta pelas instituições das respectivas classes.

Em relação a última modernização trabalhista no Brasil ${ }^{1}$, os empresários por meio de suas instituições classistas impuseram mudanças na legislação social com a finalidade de retomar, segundo seus interesses e concepções, o crescimento econômico e superar os altos custos da força de trabalho e os empecilhos proporcionados pelas leis trabalhistas (legislado).

As intervenções da Confederação Nacional da Indústria (CNI) e da Federação das Indústrias do Estado de São Paulo (FIESP) radicalizaram na direção da privatização, redução de direitos sociais e, por conseguinte, desconsideraram qualquer perspectiva de soberania nacional. Portanto, para compreendermos a ação dessas entidades classistas e suas ideologias que reivindicaram a modernização trabalhista, primeiramente, abordamos as classes sociais no Brasil e, posteriormente, as principais causas e efeitos da contrarreforma trabalhista.

\section{A SOCIEDADE DE CLASSES NO CAPITALISMO DEPENDENTE}

Ao observarmos as classes sociais no Brasil, notamos que as elites ${ }^{2}$ nacionais somente conseguem exercer suas personificações de classe dentro do caráter global do

\footnotetext{
1 Entendemos que a Lei $\mathrm{n}^{\circ}$ 13.467, de 13 de julho de 2017 (BRASIL, 2017) em muito materializa a contrarreforma trabalhista. Contudo, outras normativas, como a Lei ${ }^{\circ} 13.429$, de 31 de março de 2017 (BRASIL, 2017b) (que autorizou a terceirização plena), bem como um conjunto de normativas editado e revisto no período, além da uniformização de jurisprudências (determinando a forma de interpretar a lei trabalhista) ou o cancelamento de muitas outras, constituem o que, aqui, entendemos como modernização trabalhista.

${ }^{2}$ De acordo com Fernandes (1968, p. 170-171): “[...] as elites das sociedades subdesenvolvidas cumprem suas funções históricas invertendo os seus papéis. Em vez de pugnar pela autonomia crescente de suas sociedades nacionais, agindo como inventores de cultura e de técnicas sociais novas, operam como agentes e principais responsáveis de uma especialização que converte aquelas sociedades em consumidoras retardatárias e frustradas do progresso sociocultural alheio".
} 
imperialismo, ou seja, elas só se constituem enquanto classe burguesa pelo caráter da dependência.

As elites nacionais precisam da dominação externa para manter seu status de privilegiamento político-social, sendo assim, não desempenham sequer uma função realmente autônoma de burguesia enquanto classe, mas representam, na verdade, uma situação de classe dominante-dominada (BAMBIRRA, 2019, p. 145). Isso faz com que novas estruturas se objetivem para todas as classes presentes na sua interação. Algo muito presente na formação social brasileira é a excessiva exploração da força de trabalho como maneira de conseguir apropriação dual do excedente econômico que precisa ser levado sua parte ao capital estrangeiro. Esse sintoma altera não apenas as condições de vida das classes trabalhadoras, mas, toda a dinâmica das relações e condições de trabalho. Podemos analisar esse fato na constituição histórica do trabalho no Brasil desde seu momento escravista até o surgimento do mercado de trabalho assalariado, pois a precarização, a informalidade, o racismo, o desemprego e a intensidade da exploração da força de trabalho são marcas constantes em nossa processualidade histórico-social.

As implicações da dependência para a classe trabalhadora é a necessidade de sua modernização dependente. Diferente acontece com as classes dominantes-dominadas, em que na sua própria constituição enquanto classe - por seu privilegiamento e status já se encontram pertencentes a ordem da dependência. A sua situação de interesses como classe dominante faz com que, mesmo sendo contraditórios seus compartilhamentos de posições pela heterogeneidade que compõe essa classe, há nela uma amálgama de poder (BAMBIRRA, 2019, p. 93) com a finalidade de defender a todo custo sua dominação.

Fernandes (2009) é preciso ao afirmar que:

A melhor palavra, de que se dispõe para designar essa conglomeração de
posições, interesses, grupos e subgrupos, formas de solidariedade de classes e
orientação básica no uso do poder político não é oligarquia, mas plutocracia.
Esta última palavra traduz, de modo imediato, o que é compartilhado em
comum e se erige em base do superprivilegiamento de classe, que é o poder
fundado na riqueza, na disposição de bens e na capacidade de especular com o
dinheiro (ou com o crédito) (FERNANDES, 2009, p. 106).

Na particularidade brasileira, o Estado se torna o instrumento por excelência das classes abastadas para decidir os rumos da modernização. É nele em que se põe em funcionamento os interesses da plutocracia através da amálgama de poder. Esse Estado também se encontra furtado de suas reais funções pelo aparelhamento da plutocracia dependente, com o propósito de defender a ordem estrutural do subdesenvolvimento. $O$ Estado está longe de conseguir se descrever como um campo real da luta de classes por excelência, como modelo representado no ideal dos países hegemônicos. Vemos, então, que o caráter da dependência infere diretamente nas instituições classistas, conferindolhes características arcaicas que se tornam indispensáveis para sua perpetuação. Por isso, o Estado no capitalismo dependente é mais do que um "Estado burguês": 
É um Estado tecnocrático submetido ao controle conservador das classes privilegiadas, graças à modernização das estruturas e funções do aparelho estatal. A centralização alcança seu ponto culminante e, com ela, a 'intervenção estatal' converte-se, de fato, no motor da revolução burguesa [...] (FERNANDES, 2009, p. 109).

O retrato mais fidedigno de todo esse cenário encontra-se nas vésperas da consolidação da contrarrevolução preventiva de 1964. Sem existir pautas ou pressões contra a ordem mas sim pautas das massas populares, de uma consolidação de desenvolvimento que rompia com o padrão dependente -, esta representou uma verdadeira ameaça para a dominação interna e externa. Tomamos como exemplo a reforma agrária. Para a dominação interna, a concentração de terras da oligarquia agrária representa seu único modelo de dominação; para a dominação externa, em um país com grande zona agrária, e exportador de matéria-prima, conceber a reforma agrária era afrontar a dominação imperialista. Nem mesmo em possível panorama de pretensa "revolução nacional", nossas elites apoiaram o que poderia lhes oferecer, inclusive, chances de exercer certa autonomização, preferiram recorrer ao golpe de Estado, neutralizando, mais uma vez, as camadas populares e recorrendo à modernização para o capital monopolista ${ }^{3}$. Este é o retrato cabal de nossa classe dominante-dominada ${ }^{4}$. Não foi por incidente que a saída do ciclo autocrático burguês desenvolveu-se, após sua crise, como uma saída lenta, gradual e segura, ou seja, a redemocratização representa uma distensão da plutocracia e seu modelo autocrático.

O processo de modernização, que rompe com o passado arcaico - mas também o carrega -, ocorre por um processo autocrático, pois este parece ser a única forma que nossa plutocracia consegue, de fato, operar sua reestruturação necessária para a modernização do passado pernicioso, criando na subjetividade das classes sociais o sentimento de despotismo esclarecido, isto é, enxerga-se o caráter autocrático como um mal necessário para o país e a única via possível para seu desenvolvimento. Todo ato burguês torna-se, então, autocrático e pró-imperialista. Essa ideologia se apresenta como alternativa fundada na formação social brasileira, alicerçada pela práxis da classe dominante. ${ }^{5}$

Através da análise das classes sociais e suas implicações sob o capitalismo dependente, podemos compreender melhor a realidade brasileira e os direitos sociais das classes trabalhadoras diante da última "reforma trabalhista". O persistente ataque à CLT é de longa data, já em 1964 tivemos o fim da estabilidade no emprego e a criação do FGTS. Foi

\footnotetext{
${ }^{3}$ Netto (2015, p. 48-49) categoriza a tentativa de modernização através do Estado autocrático burguês, instaurado a partir da contrarrevolução preventiva de 1964, como modernização conservadora. A palavra acolhe bem a dialética do arcaico com o moderno presente em todo processo de desenvolvimento. Sua obra contém importante síntese do processo autocrático burguês e suas implicações ideoculturais.

4 "Se já houve, alguma vez, um 'paraíso burguês', este existe no Brasil, pelo menos depois de 1968" (FERNANDES, 1976, p. 359).

${ }^{5}$ Exemplo de despotismo esclarecido ocorre no pretenso milagre econômico legado pela autocracia burguesa que ocorreu pelo investimento do capital estrangeiro e, que mais tarde, culminou na grande dívida externa. Esse palco histórico contou também com uma guinada dos direitos sociais, até antes escassos internamente, induzida pelo Estado tecnocrático como maneira de se legitimar a autocracia burguesa.
} 
o primeiro passo na direção da modernização/flexibilização trabalhista no Brasil (ALVES, 2017, p. 98).

É nesse sentido que toda realização necessária à dependência e ao capital monopolista é transferida ao Estado tecnocrático. Esse é o ponto decisivo para o entendimento dos processos em curso no Brasil. Ante essa conjuntura, operar a modernização ou a reestruturação necessária para a acumulação dual de capital é a ordem do dia. Já desde a década de 1990 o Estado brasileiro lançou mecanismos necessários a acumulação de capital sobre a alcunha de "reforma". As "reformas" tornaram-se panaceias perfeitas para mudar o passado subdesenvolvido, indesejável e se ajustar a ordem neoliberal. $\mathrm{O}$ progresso, que se formula nos moldes do capital, apresenta-se contraditoriamente como um "estado ótimo do passado", isto é, o "paraíso burguês" das classes dominantesdominadas e o terror das classes subalternas.

Portanto, o presente sempre se mostra como anomalia do subdesenvolvimento, como se fosse produto de seu próprio processo interno. Nesse formato, em que o quadro indesejável é atônito, para tornar a práxis social das classes populares consciente por qualquer ideologia que promova uma modernização, é preciso, sobretudo, renegar o passado. A tônica da "reforma trabalhista" demonstra a maneira de operação da realidade neoliberal: torna a aparência das coisas, em sua imediaticidade, algo paliativo enquanto o processo real se dá na essência e estrutura da realidade histórica. Expondo mais nitidamente: alteram-se as palavras para - a "reforma"/modernização em particular - suceder o seu oposto. Nesse caso, não se trata verdadeiramente de "reformas" que se operam, mas sim de contrarreformas que consolidam a modernização do capitalismo dependente.

\section{CNI E FIESP: A IDEOLOGIA DA MODERNIZAÇÃO}

O Estado tecnocrático, nos moldes neoliberais e modernizado, tem na sua operacionalidade o campo estratégico. Pelo Estado promove-se sua própria ruína, numa espécie de "autocrítica", mas que esconde suas reais intenções. Todas as mazelas presentes no dinamismo dependente e subdesenvolvido cabem a culpa no modus operandi, quase sempre dirigida pelo Estado e para o Estado ${ }^{6}$. De nenhuma forma pretende-se descarrilhar sua verdadeira forma, apenas utilizar o arsenal preciso, isto é, o próprio Estado, para as finalidades necessárias oriundas das exigências do mercado mundial. É nesse limiar que se situam as contrarreformas que insistentemente tentam modernizar conservadoramente. A ideologia burguesa, mesmo no cenário da América Latina dependente, exige do Estado ser um órgão de conciliação de interesses dificilmente tratam como conciliação de classes, pois seria alegar que existem luta de classes - para o bem comum da sociedade. Nas práticas recentes do Estado brasileiro, em

\footnotetext{
6 "O Estado jamais encontrará no 'Estado e na organização da sociedade' o fundamento dos males sociais. [...] Quando o Estado admite a existência de problemas sociais, procura-os ou em leis da natureza, que nenhuma força humana pode comandar, ou na vida privada, que é independente dele, ou na ineficiência da administração, que depende dele. [...] Finalmente, todos os Estados procuram a causa em deficiências acidentais ou intencionais da administração e, por isso, o remédio para os seus males são medidas administrativas. Por quê? Exatamente porque a administração é a atividade organizadora do Estado". (MARX, 2010, p. 58-60).
} 


\section{temporalis}

especial no conjunto das contrarreformas, observa-se o comando exercido dentro desse aparelho, o que evidencia ser um órgão de dominação de classes para os interesses da plutocracia. As contrarreformas que ocorrem sob o jugo neoliberal, promovidas ideologicamente como "reformas" que precisam ocorrer e são irreversíveis", comprovam no seu âmago esse estágio de dominação de classe pelo Estado.

Dessa maneira, as desmedidas para acionar as mudanças necessárias ao capital, operacionalizadas pelas contrarreformas, simboliza o algoz da classe trabalhadora. No caso brasileiro, em que a precarização já é constitutiva da nossa formação socioeconômica, é preciso ideologizar essas mudanças para que o hic et nunc de nossa precarização possa coadunar com os interesses externos, no propósito de manter a ordem da classe dominante-dominada, isto é, perpetuar a dependência em todas as esferas da sociedade. Essas ideologias precisam correr na ordem do tempo do capital. Mesmo com todas as determinações, da simbiose entre a reestruturação produtiva e o neoliberalismo, é preciso tornar a práxis operante da sociedade em práxis manipulada que corresponda sempre com o tempo presente. Vejamos agora como esse paradigma ocorreu no Brasil com a contrarreforma trabalhista de $2017^{8}$.

O processo de precarização legal, legítima, criminosa e reconhecida pelo Estado brasileiro começa a ocorrer "[...] na noite de 22 de março de 2017, [quando] mais um duro golpe foi desferido contra a classe trabalhadora brasileira. A Câmara dos Deputados aprovou, por 231 votos, o projeto de terceirização completa das relações de trabalho (PL 4302/98 que se tornou Lei 13.429/17)" (LARA, 2018, p. 34). Esse projeto encontrava-se em curso desde 1998, época do governo de Fernando Henrique Cardoso, que pretendia atender as exigências dos seus principais beneficiados: a FIESP e a CNI. No documento 101 Propostas de Modernização Trabalhista da CNI - entregue através dos empresários da indústria para o parlamento e o governo federal -, de 2012, entre suas propostas para a modernização se encontrava a terceirização das atividades-fim. O discurso para a aprovação da terceirização total era de que iria ocasionar maior produtividade e competitividade no mercado de trabalho. Contraditoriamente assistimos no ano posterior de sua aprovação a estagnação da produtividade; o mesmo cenário passa a ocorrer nos anos subsequentes.

\footnotetext{
7 Paulo Skaf, presidente da FIESP, usou a mesma estratégia para aprovação da contrarreforma trabalhista: "Desta vez não há mais tempo. As reformas são necessárias, para o bem do país, para o futuro do país, para a retomada do crescimento, que é do que o Brasil mais precisa agora, para recuperar os empregos que perdeu, para recuperar as empresas que perdeu, para que as prefeituras, os governos arrecadem mais, sem o aumento de impostos. Estamos no caminho" (FIESP, 2016, não paginado).

${ }^{8}$ Apesar de o objetivo de nossa exposição não ser uma análise em si das implicações e os efeitos da contrarreforma trabalhista sob a Lei 13.467/2017, mas sim suas causas ideológicas, não nos furtaremos de expor, ainda que em traços gerais, algumas de suas especificidades. Grande parte dessa análise pode ser encontrada de forma exemplar em: Inácio e Lara (2018) com um tratamento particular sobre a questão da saúde do trabalhador; Mattei e Heinen (2019) a partir de um quadro geral das implicações no Estado com maior produtividade; Alves (2017) para uma denúncia do desmonte da CLT como um fenômeno presente desde a autocracia burguesia; Ferrer e Alves (2018) assinalando as implicações da contrarreforma trabalhista pelo interesse do empresariado brasileiro; Krein, Oliveira e Filgueiras (2019) numa síntese das implicações nas esferas possíveis que compõe o universo trabalhista e com riqueza na análise de dados estatísticos.
} 
A ampliação da terceirização resulta em aumento da rotatividade e mais acidentes de trabalho. Vejamos alguns dados do mercado de trabalho:

O tempo de permanência no trabalho é de 5,8 anos para os trabalhadores
diretamente contratados, em média. Para os terceirizados é de 2,7 anos. A
jornada de trabalho dos terceirizados é de cerca de 7,5 horas a mais por semana
em relação aos trabalhadores formais. Entre dez acidentes de trabalho
notificados no Brasil, nove são terceirizados. A remuneração de um terceirizado
é, em média, 24,7\% menor que a de outros trabalhadores que exercem a mesma
atividade (DIEESE apud LARA, 2018, p. 34).

Se buscarmos compreender, na lógica da dependência, esse quadro se mostra de forma perfeita para a acumulação dual de capital, isto é, a superexploração da força de trabalho. A exigência global da precarização do trabalho pelo imperialismo tem rebatimento maior na especificidade do subdesenvolvimento brasileiro. Apesar da terceirização marcar forte expoente para precarização do trabalho no Brasil, ela não opera isoladamente. A informalidade também presente na formação do nosso mercado de trabalho fechava o ano de 2017 abarcando 37,3 milhões de pessoas. A parcela dos trabalhadores informais é aquela que não contam com qualquer laço formal de contratação ou regulamentação de sua força de trabalho, eles chegam a ganhar, em média, $44 \%$ menos do que os trabalhadores formais.

Ainda no mesmo ano da contrarreforma trabalhista, o número de desempregados chegava em 13 milhões de pessoas, sem levar em conta os desalentados, o que somaria um desemprego total de 26,6 milhões (FILGUEIRAS, 2019, p. 35). Foram eles, os desempregados, que foram utilizados de forma ideologizante para a contrarreforma trabalhista. A promessa de Henrique Meirelles, na época enquanto Ministro da Fazenda, era que a "reforma" deveria gerar mais de 6 milhões de empregos, ou seja, abarcava quase $50 \%$ dos desempregados (não levando em conta os desalentados). Não tardaram para fazer ressurgir os jargões da produtividade e competitividade. Afirmavam veementemente que, aprovada a contrarreforma trabalhista, teriam mais oportunidades de investimento nas empresas (CNI, 2017b, p. 4). Nada disso aconteceu, a produtividade como já vimos - ficou estagnada; os investimentos empresariais em seus setores vêm diminuindo (FILGUEIRAS, 2019, p. 34) e; a competitividade não resultou para o empresário, mas sim um fardo que recaiu sobre o trabalhador, pois agora os trabalhadores precisam competir no mercado de trabalho para ver quem consegue vender sua força de trabalho por um salário menor.

Nos documentos do empresariado industrial brasileiro, particularmente da CNI e FIESP, em especial o intitulado 101 Propostas para a Modernização Trabalhista", de 2012, afirmava que era preciso "[...] conciliar o desenvolvimento econômico com a coesão social" (CNI, 2012). A "coesão social” apontada não teve ocorrências durante o processo de formulação da nova legislação social trabalhista no Brasil, predominou os interesses econômicos em jogo: após longa oposição do Tribunal Superior do Trabalho e da maioria dos sindicatos, a proposta foi aprovada com pressa e sem quaisquer formas de diálogo no Congresso Nacional e no Senado. Mesmo assim, o presidente da FIESP, em coletiva afirmava, antes da aprovação da Lei 13.467/2017 (BRASIL, 2017a), que se há um consenso 


\section{temporalis}

no país é que "não há alternativa" senão a vigência da nova lei ${ }^{9}$. Sem escrúpulos, seguindo os desastrosos resultados possíveis para a economia interna pós-aprovação, o alto escalão da burguesia industrial reverbera à nação que após um ano de vigência da contrarreforma trabalhista, ela conseguiu atingir seus objetivos propostos, entre eles: "[...] garantia dos direitos ao trabalhador, segurança jurídica e geração de empregos" (BAGATINI, 2018, não paginado). A "segurança jurídica" foi tornada propriedade do empresariado e; a "geração de empregos" em todos os anos subsequentes foi um cenário trágico ${ }^{10}$, sem contar com o constante aumento da informalidade ${ }^{11}$.

Nos documentos da $\mathrm{CNI}$, era recorrente a afirmação de que o custo do trabalhador formal é muito grande e que os direitos trabalhistas trazem muitas inseguranças jurídicas às empresas (CNI, 2012). Como, então, a partir desses relatos podem afirmar que a "garantia dos direitos do trabalhador" foi alcançada? Trata-se puramente de uma falsa ideologia, uma vez que contém ipsis litteris o objetivo central de sua intervenção no conflito de classes com o seguinte método:

[...] foi identificado um conjunto significativo de situações que, do ponto de vista empresarial, poderiam ser mais bem equacionadas. Em cada uma delas, buscouse identificar uma 'irracionalidade' que caracterizasse um problema e, em seguida, avaliaram-se seus impactos negativos. Com base nesses elementos, foram então elaboradas as propostas, relacionados os ganhos esperados e especificadas as medidas necessárias para sua implantação (CNI, 2012, não paginado).

Ou seja, do ponto de vista empresarial para o empresariado, sendo que todo e qualquer direito trabalhista representa um "irracionalismo" negativo e a saída é apresentada pelo próprio empresariado ${ }^{12}$. Em documento posterior à aprovação da contrarreforma trabalhista o discurso empresarial se altera, alegando que agora "com a nova lei se abre um horizonte de mais segurança jurídica e cooperação, proporcionando a melhoria do ambiente de negócios, o que contribuirá com o crescimento econômico, beneficiando as empresas, os empregados, enfim, o Brasil” (CNI, 2017a, não paginado).

Outra estratégia empresarial formulada foi culpar a Previdência Social que arcava muitos custos em razão da mudança demográfica, e que com a modernização trabalhista iria conseguir reverter esse quadro (CNI, 2012). Insatisfeitos, após a vigência da contrarreforma trabalhista praguejaram constantemente contra a Previdência Social resultando, em 2019, na contrarreforma da Previdência, com o argumento de que o modelo de aposentadoria no Brasil era deficitário ${ }^{13}$.

\footnotetext{
${ }^{9} \operatorname{FIESP}(2016)$.

${ }^{10}$ IBGE (2019).

${ }^{11}$ Coll (2020).

${ }^{12}$ O "irracionalismo" parece acompanhar Paulo Skaf, presidente da FIESP, em coletiva de imprensa afirma que a CLT é um "emaranhado de leis" e que, por outro lado, ela é "frágil” (TONI, 2015). É de curiosa notabilidade ver a intensa oposição da FIESP (2013) acerca da redução da jornada de trabalho, mas sua sagacidade em diminuir a regulamentação de jornada de trabalho sobre o trabalho parcial.

${ }^{13} \mathrm{O}$ livro da Federação das Indústrias do Estado de São Paulo (FIESP), Livre para crescer: proposta para um Brasil moderno (ZOCKUN et al., 1990), é o maior exemplo da modernização trabalhista pretendida. Livro que foi elaborado para oferecer parâmetros à economia brasileira durante as crises de 1980 e 1990 . Os
} 
Em 2016 a CNI apresentou o documento 119 Propostas. Neste documento reitera-se "[...] as propostas de flexibilização da legislação do trabalho no Brasil com o objetivo de reduzir o custo do trabalho para aumentar o lucro das empresas" (SILVA, 2017, p. 238). As propostas na esfera jurídica mereceram maior destaque nesse documento, em que sintetizavam todas as orientações do Documento Técnico 319 do Banco Mundial de 1996, que previam "reformas" do setor judiciário dos países periféricos, orientados pelos interesses do paradigma neoliberal (SILVA, 2017, p. 236). O objetivo era esvaziar quaisquer formas de influência jurídica da Justiça do Trabalho, usando todas as artimanhas possíveis a favor do empresariado, como, por exemplo, suspender a vigência das empresas ligadas à lista de trabalho escravo (SILVA, 2017, p. 237). Elucida-se, assim, o motivo de alegar que após a aprovação da contrarreforma trabalhista de 2017 a "segurança jurídica" e a "cooperação" aumentaram. Com a incriminação de qualquer forma de justiça, fiscalização e direito do trabalho, o interesse empresarial enquadrou as modificações da CLT para sua "segurança jurídica".

A prova cabal de não ter sido uma partida em vão para a burguesia, foi o aumento da taxa de lucro pelo empresariado, e que contraditoriamente não investiu em seu setor produtivo (FILGUEIRAS, 2019, p. 34). Torna-se explícito aqui a plutocracia presente em sua amálgama dirigindo um Estado tecnocrático, que numa situação de dependência precisa realizar suas transformações necessárias, pela via da modernização, através de um despotismo esclarecido. Esse despotismo, com todos os vieses ideológicos presentes, vai desvelando sua verdadeira face, a face do capital na materialidade cotidiana. A sociedade de consumo do capital monopolista, em seu âmbito dependente, já não consegue ser atuante sem levar à completa miséria seus trabalhadores. A contrarreforma trabalhista enquanto fenômeno ocorre como reação à dependência da nação ao capital monopolista e imperialista, mas o que é preciso salientar é que essa atuação vem ocorrendo desde a contrarrevolução preventiva de 1964. Sua aliança com o Estado neoliberal só reforça as características com que ela ocorre. As contrarreformas dos últimos anos no Brasil apresentam o aprofundamento do subdesenvolvimento, onde o que importa é prioritariamente a dual extração de mais-valor do que o crescimento econômico, produtividade e condições de competitividade da indústria nacional.

A particularidade da dependência faz com que nossa classe dominante-dominada fique até mesmo refém das formas em que se dão o desenvolvimento no país. Mesmo que essa classe objetiva o impulsionamento do setor produtivo ele só se torna eficaz - e só

argumentos antecipam e apresentam a posição da burguesia industrial brasileira a favor das "reformas" e
"modernizações" implementadas no Brasil recentemente. Dentre as reformas e modernizações
pretendidas no documento da FIESP, destaca-se: as privatizações; a reforma da previdência, a reforma das
legislações trabalhistas (ênfase na livre negociação entre capital e trabalho); inserção subordinada do Brasil
na economia internacional; abertura ao capital internacional (crescimento do IED); desestruturação
completa do movimento sindical; recomendação para que a inserção internacional do Brasil fosse feita pela
revalorização da agricultora de exportação. Para fins de ilustração, citamos o que se pensava sobre os
direitos sociais: “Isso é difícil de transmitir, mas será necessário enfatizar que todos (os trabalhadores)
terão que trabalhar mais horas. Necessitaremos de uma reforma constitucional no capítulo dos direitos
sociais. Isso só será possível se o medo for bem conscientizado pelo povo e, em especial, pela classe média.
Será facilitado ainda pelo uso adequado da popularidade temporária do presidente vitorioso" (ZOCKUN et
al., 1990, p. 258). 


\section{temporalis}

consegue ser operante - dentro da ordem heteronômica, isto é, o processo de desenvolvimento ocorre numa relação de dependência que não permite uma independência, autonomia ou qualquer mudança fora da ordem ${ }^{14}$. Dessa forma, conseguimos até mesmo compreender a atitude do empresariado brasileiro em não priorizar o investimento produtivo, pois o que se apresenta vantajoso para as elites é se manterem na ordem e no topo, não importando o estado anormal das coisas. O desenvolvimento só se torna um critério preciso para as elites a partir do momento em que a "ordem do tempo" do capital mundial monopolista exige sua modernização, para não colapsar no tempo. Nesse processo, o que se torna imperioso é manter a práxis de classe dirigente que movimenta todos os dinamismos da sociedade atuando dentro da ordem.

Dentre os representantes da ideologia burguesa que atuaram nas contrarreformas (trabalhista e previdenciária), situa-se Rogério Marinho, relator da contrarreforma trabalhista. Em 2018, no seu livro Modernização das Leis Trabalhistas: o Brasil pronto para o Futuro, o deputado busca defender em suas 183 páginas a Lei 13.467/2017 (BRASIL, 2017a). Dotado de alto teor ideológico decadente, dependente e entreguista, a estratégia utilizada pelo autor do livro foi principalmente acusar todo o passado do governo precedente, que já se encontrava esgotado, e desejar a modernização como a panaceia para todos os males em que se encontravam no mercado de trabalho. Marinho assinala que as modernizações ocorridas até então ainda não eram suficientes, dentre as propostas presentes em seu livro, podemos encontrar indicações: da contrarreforma sindical; da contrarreforma previdenciária - que se objetivou em 2019; da necessidade de uma simplificação tributária e; por último, de uma contrarreforma política (MARINHO, 2018).

Não obstante, Marinho (2018) patenteia os opositores das modernizações trabalhistas como "[...] amantes da luta de classes [...]" (MARINHO, 2018, p. 43) e em contraste afirma que "[...] o equilíbrio entre capital e o trabalho é essencial para a confiança do sistema. Ter regras justas para o empregador e o trabalhador é condição essencial para que o Brasil volte a gerar empregos" (MARINHO, 2018, p. 112). Não se trata, portanto, de negar a luta de classes quando aceita o antagonismo entre capital e trabalho, mas cunhá-la estrategicamente como motivo ideológico ${ }^{15}$. Ainda, no mesmo sentido dos documentos da CNI, há a sustentação do deputado de que agora reina a "segurança jurídica". A cartada final de seu livro é a observação de que se trouxe "[...] a lei que era da metade do

\footnotetext{
${ }^{14}$ De acordo com Cardoso (2018): "[...] o grosso das empresas industriais tem os centros de decisões estratégicas no campo da tecnologia, fora do Brasil. O país é importador de tecnologias de fora. Quando ocorre uma mudança tecnológica como agora, o Brasil fica para trás. O fato de não haver centros de desenvolvimento de tecnologias no Brasil implica que o grau de inovação é mais baixo. Se o grau de inovação é mais baixo, a produtividade é menor, a dinâmica da indústria é menor e assim por diante" (CARDOSO, 2018, p. 63).

${ }^{15} \mathrm{O}$ trato mais esclarecedor do cunho ideológico burguês de seu livro é a presença constante contra as regulamentações trabalhistas na afirmativa que elas representam um ônus para o mercado de trabalho, e logo em seguida o relator da contrarreforma trabalhista admite: "[...] não sou advogado, mas sei que o direito, segundo o senso comum do empregador, é um grande obstáculo para empreender". (MARINHO, 2018, p. 63).
} 
século XX para o século XXI, para o espírito do nosso tempo (MARINHO, 2018, p. 71, grifo nosso).

Depois de ter reduzido a CLT ao interesse restrito do empresariado; após legalizar a precarização pelas novas modalidades de trabalho, pelo aumento da jornada de trabalho, pela possibilidade de se trabalhar grávida dentro de locais insalubres, de cunhar uma falsa assimetria entre patrão e empregado, de desintegrar a atividade sindical, de fato, como assinala Rogério Marinho, a lei veio para o espírito do nosso tempo, isto é, o tempo do capital.

O tempo do capital mundial pós-reestruturação produtiva e sob a égide do neoliberalismo precisa operar constantemente a precarização do trabalho como forma de elevar suas taxas de lucro. Para objetivar tal feitio todas as apologias escatológicas fazem seu dever enquanto parâmetro ideológico de intervenção de classe nos conflitos sociais. No Brasil, o que vimos foi o empresariado praguejar acerca da regulamentação trabalhista, como maneira de modificá-la a seu bel-prazer. Para o trabalhador que conta como sua única forma de reprodução da vida a venda de sua força de trabalho, este golpe simboliza o desmonte de suas condições de vida. Se por um lado, a contrarreforma trabalhista de 2017 precariza ainda mais as relações de trabalho, por outro lado, ela se utiliza do próprio direito como maneira de operacionalizar tal condição. Essa foi a tática de difundir e propagandear ideologicamente que a contrarreforma trabalhista não retirou direitos, mas ampliou-os às necessidades das mudanças que ocorreram no mercado de trabalho; o que no imediatismo da análise se torna verdade, contudo, em suas determinações sóciohistóricas guardam múltiplas contradições.

Em suma, o que ocorre é o direito enquadrando a precarização e, assim, legalizando-a. Abaixo destacamos alguns dos principais efeitos da modernização trabalhista:

- o fim da contribuição sindical demonstra-se claramente como uma forma de desintegrar a atuação dos sindicatos trabalhistas;

- a nova forma de aumento da jornada de trabalho é uma maneira de aumentar em princípio a extração de mais-valor absoluto, mas que analisado de maneira mais ampla pode ser notado conjuntamente com a extração de mais-valor relativo, visto a necessidade da polivalência como forma de intensificação do trabalho e substituição do capital variável. O aumento da jornada de trabalho, combinada com a nova modalidade de trabalho intermitente, permite que o empregador contrate à sua vontade a demanda de capital variável que necessite, determinando na escala $12 \times 36$ a efetivação de trabalho vivo preciso para a execução do processo de trabalho de maneira ininterrupta. Um exemplo disso é uma empresa que funcione apenas nos dias úteis, com seu local aberto $12 \mathrm{~h}$ por dia: esta empresa precisaria apenas de dois trabalhadores intermitentes alternando seus dias para que a empresa pudesse ter um trabalhador em cada dia da semana trabalhando por $12 \mathrm{~h}$ no posto de trabalho. Desta forma, sua produção ficaria ininterrupta e com aumento da jornada de trabalho em $4 \mathrm{~h}$;

- a nova modalidade de trabalho, o trabalho intermitente, em seus efeitos torna-se a maneira perfeita de tornar o trabalhador refém da demanda do capital, uma vez que para esse trabalhador só existe trabalho se o empregador necessitar de sua 
força de trabalho. Assim, este trabalhador precisa estar sempre com sua força de trabalho disponível sem saber quando será chamado, não possuindo vínculo rotineiro com a empresa contratante. Essa é a máxima da demanda nos alicerces da propriedade privada: o trabalhador é pertencente à empresa, porém só atuante quando a demanda do capital o clama para reavivar o trabalho morto. Como vimos acima, essa nova modalidade combinada com o aumento da jornada de trabalho é a expressão de um trabalho precário por completo;

- a redução na regulamentação da jornada de trabalho do trabalhador parcial é uma maneira de enquadrar pelo direito, ou seja, legalizar a subutilização da força de trabalho além de precarizar ainda mais essa modalidade que já simbolizava a subutilização. Assim, os trabalhadores precisam recorrer a outras formas de trabalho, conjuntamente com essa, para complementar sua renda;

- a Justiça do Trabalho foi totalmente colocada a favor do capital em detrimento do trabalho, esse, talvez, seja o motivo do empresariado ter "maior segurança jurídica” após sua aprovação. Construindo a insegurança nos trabalhadores pela Justiça do Trabalho com suas novas formas de atuação, o capital teve no despotismo sua verdadeira representação. Tal regulamentação, no país onde os acidentes de trabalho são constantes ${ }^{16}$ e conta com vários casos de trabalho análogo à escravidão ${ }^{17}$, demonstra-se uma prática criminosa;

- o negociado sobre o legislado infere pelo direito sua própria negação enquanto regulamentação trabalhista. O objetivo é colocar a decisão de forma individual entre empregador e empregado acima da lei, causando uma falsa assimetria de lados com interesses comuns em suas decisões;

- a permissão das gestantes trabalharem em locais insalubres com apresentação de atestado médico, mostra por si só o lado pérfido do capital que não respeita sequer a vida, mas sim a extração de mais-valor em primeiro lugar. A parcela das mulheres trabalhadoras, já contando com a desigualdade salarial - que representa em média 20,5\% - e jornadas de trabalho mais extensa do que os homens, tem sido duramente afetada pelas contrarreformas do capital.

O direito enquanto complexo social (LUKÁCS, 2013), definido pela práxis social humana, torna-se terreno de dominação de classe oriunda da própria luta de classes. A ideologia, enquanto complexo que estabelece suas relações com outros complexos, tem na materialidade da conjuntura brasileira, no direito e na política, seus pontos basilares. $\mathrm{O}$ empresariado brasileiro não satisfeito e, sobretudo, para atender as necessidades do capital interno e externo, apologeticamente continua a reclamar do "emaranhado" de regulamentações trabalhistas. A ideologia do empresariado brasileiro na operacionalização das suas contrarreformas só encontra um obstáculo: o limite físico do

\footnotetext{
${ }^{16}$ O Brasil ocupa a quarta posição no ranking mundial de acidentes de trabalho. A Previdência Social registra por ano cerca de 700 mil casos, e, segundo dados do Observatório Digital de Segurança e Saúde do Trabalho, o país chega a contabilizar uma morte por acidente em serviço a cada três horas e 43 minutos. 17 “Desde que o governo brasileiro reconheceu a existência dessa prática ilegal e passou a combatê-la, em 1995, os grupos de fiscalização da Inspeção do Trabalho resgataram 53.607 trabalhadores nessa condição em todo o país" (EM 2018..., 2019, não paginado).
} 
trabalhador. Até este não se esgotar, a burguesia nacional usará todas as estratégias possíveis para adequar as exigências possíveis à extração de suas taxas de lucro ${ }^{18}$.

\section{CONSIDERAÇÕES FINAIS}

A burguesia industrial brasileira, enquanto classe dominante-dominada, opera ideologicamente o discurso falso de que muitos direitos trabalhistas entravam o mercado de trabalho, mas na verdade é apenas uma forma ideológica de operacionalizar sua extração dual de capital que precisa demolir os direitos sociais.

A CNI e a FIESP, como entidades ideológicos do empresariado industrial brasileiro, representam a plutocracia in nuce buscando todas as formas possíveis de atuação para seus ganhos particulares. A ideologia de desmonte dos direitos trabalhistas no Brasil e culpabilização do trabalhador desempregado ganham muitas expressões. O jornal Estado de S. Paulo, em longa matéria, não hesita em culpar individualmente os desempregados que não aproveitam seu tempo para fazer cursos de requalificação ${ }^{19}$.

A ideologia do trabalho sem direito e precarizado se expressa, por exemplo, dentro das empresas na condição de assédio moral, como é o caso do empresariado da Livraria Cultura - a família Herz - que sem pensar duas vezes, numa convocação de reunião com seus “colaboradores", que protestavam de diversas formas acerca do não depósito da empresa de seus respectivos FGTS e das condições de trabalho, em tom de ameaça, o Sr. Herz, realmente explicita-nos o que é a "colaboração": "Você não é a Livraria Cultura. Eu sou a Livraria Cultura, você não! Você está aqui hoje e amanhã pode não estar mais”. O Sr. Herz não hesita em demonstrar o seu verdadeiro interesse e segue adiante: "Graças a esse novo governo, não vai ter mais essas frescuras de leis trabalhistas que só atrapalham, está flexibilizando tudo, o que não pode, vai poder e logo mais vai poder tudo, tudo vai ser flexível!" 20 .

Portanto, a precarização do trabalho sem direitos é o espírito do tempo, como acertadamente cunhou Rogério Marinho. A desmedida ideológica do capital proclamada pelo empresariado brasileiro coloca a assertiva da modernização que carrega as estruturas sócio-históricas da formação social do Brasil. O empresariado confirma sua dominância e, dessa maneira, dirige o Estado tecnocrático ${ }^{21} \mathrm{com}$ suas contrarreformas para manter a ordem do capitalismo dependente.

\footnotetext{
${ }^{18}$ Exemplo disso é o momento de pandemia que estamos vivendo. Em meio a tal cenário mundial, a $\mathrm{CNI}$, aproveita-se para lançar notas exigindo mais contrarreformas no mercado de trabalho (CRISE..., 2020).

${ }^{19}$ Chiara (2020).

${ }^{20} \mathrm{O}$ caso da Livraria Cultura e a efervescente luta de classes que se estabelece há alguns anos dentro da empresa nos revela também como se dá as formas de exploração nos setores de serviço (NOSSO..., 2020).

${ }^{21}$ Finalizamos este artigo, dia 22 de abril de 2020, em plena crise mundial do coronavírus. Como sabemos, o Estado não é neutro, ele é comandado pelas burguesias de cada país. E de acordo com Cardoso (2020, p. 3): “Os governos querem resolver o problema da classe que manda no governo. Obviamente há diferenças importantes, no tratamento dos trabalhadores da periferia e do centro capitalista diante da pandemia mundial. Os países imperialistas, como drenam riqueza do mundo todo podem se dar ao luxo de tratar de forma diferenciada suas respectivas classes trabalhadoras. Os repasses diretos de dinheiro, que alcançarão a maior parte dos cidadãos norte-americanos, serão de 1.200 dólares por pessoa adulta e 500 dólares por cada menor de idade. Essa ajuda direta aos cidadãos poderá alcançar 500 bilhões de dólares. O plano prevê
} 


\section{REFERÊNCIAS}

ALVES, Giovanni. O minotauro brasileiro: reforma trabalhista e desenvolvimento do capitalismo histórico no Brasil. Revista do Tribunal Regional do Trabalho da 15 Região, v. 1, p. 97-108, 2017.

BAGATINI, Fernanda. Reforma trabalhista completa um ano nesta sexta-feira. Rádio Guaíba, [S. I.], 12 jul. 2018. Disponível em: https://guaiba.com.br/2018/07/12/reformatrabalhista-completa-um-ano-nesta-sexta-feira/. Acesso em: 11. Abril. 2020.

BAMBIRRA, Vânia. O Capitalismo Dependente Latino-americano. Florianópolis: Insular, 2019.

BRASIL. Lei $\mathbf{n}^{\circ} \mathbf{1 3 . 4 6 7}$, de 13 de julho de 2017. Altera a Consolidação das Leis do Trabalho (CLT), aprovada pelo Decreto-Lei ${ }^{\circ} 5.452$, de $1^{\circ}$ de maio de 1943 , e as Leis $n_{-}^{\circ} 6.019$, de 3 de janeiro de 1974, 8.036, de 11 de maio de 1990, e 8.212, de 24 de julho de 1991, a fim de adequar a legislação às novas relações de trabalho. Brasília, DF: Presidência da República, $2017 a$.

BRASIL. Lei $n^{\circ}$ 13.429, de 31 de março de 2017. Altera dispositivos da Lei $n \stackrel{0}{6} 6.019$, de 3 de janeiro de 1974, que dispõe sobre o trabalho temporário nas empresas urbanas e dá outras providências; e dispõe sobre as relações de trabalho na empresa de prestação de serviços a terceiros. Brasília (DF), 2017b. Disponível em: http://www.planalto.gov.br/ccivil_03/_Ato2015-2018/2017/Lei/L13429.htm. Acesso em: 14 mar. 2020.

CARDOSO, José Álvaro Lima. Os desafios do Brasil no Contexto da Quarta Revolução Industrial: emprego e outras implicações sociais. In: INÁCIO, José Reginaldo; LARA, Ricardo (org.). Trabalho, saúde e direitos sociais. Bauru: Canal 6, 2018.

CHIARA, Márcia de. Quase 80\% dos desempregados não estão fazendo cursos de requalificação para conseguir uma vaga. Estadão, 12 mar. 2020. Disponível em: https://economia.estadao.com.br/noticias/geral,quase-80-dos-desempregados-nao-estaofazendo-cursos-de-requalificacao-para-conseguir-uma-vaga,70003229304. Acesso em: 12 abr. 2020.

CNI. 101 propostas para a modernização trabalhista. Brasília (DF), 2012.

também uma linha de crédito de 367 bilhões de dólares para pequenas e médias empresas, e um fundo de 500 bilhões para indústrias, cidades e estados. Os trabalhadores demitidos receberão o seguro-desemprego durante quatro meses, no valor habitualmente pago em seu respectivo estado, mais um valor extra de 600 dólares. Vejam a comparação entre Brasil e EUA: este país está colocando em marcha um plano de combate à crise que até garante um dinheirinho para os trabalhadores, ainda que o grosso dos recursos esteja direcionado às empresas. No Brasil, destinaram míseros $\mathrm{R} \$ 600,00$ para os trabalhadores mais precarizados, só que, para uma boa parte da população, que já está passando fome, o dinheiro ainda não chegou. Mas os EUA é um país rico, que explora o mundo todo para manter o seu padrão, enquanto o Brasil no pós golpe de 2016, é praticamente uma colônia dos EUA". 
CNI. Modernização trabalhista: Lei n 13.467 , de Julho de 2017, panorama anterior e posterior à aprovação. Brasília (DF), $2017 a$.

CNI. Sondagem Especial: Reforma Trabalhista. Indicadores CNI, Brasília (DF), ano 18, n. 3, dez. 2017b.

COLL, Liana. Aumento da miséria e informalidade marcam os dois anos da Reforma Trabalhista. DomTotal, Economia, [S. I.], 5 jan. 2020. Disponível em:

https://domtotal.com/noticia/1413160/2020/01/aumento-da-miseria-e-informalidademarcam-os-dois-anos-da-reforma-trabalhista/. Acesso em: 12. Abril. 2020.

CRISE mundial em função do Coronavírus reforça a necessidade de reformas no país, afirma CNI. Agência de Notícias CNI, Brasília (DF), Economia, 12 mar. 2020. Disponível em: https://noticias.portaldaindustria.com.br/noticias/economia/crise-mundial-em-funcao-docoronavirus-reforca-a-necessidade-de-reformas-no-pais-afirma-cni/. Acesso em: 14 mar. 2020.

EM 2018, fiscais identificaram 1,7 mil casos de trabalho escravo no Brasil. O Globo, Economia, [conteúdo exclusivo para assinantes], São Paulo, 28 jan. 2019. Disponível em: https://oglobo.globo.com/economia/em-2018-fiscais-identificaram-17-mil-casos-detrabalho-escravo-no-brasil-23409423. Acesso em: 12 abr. 2020.

FERNANDES, Florestan. Os desenraizados. In: . A Constituição Inacabada: Vias Históricas e Significado Político. São Paulo: Estação Liberdade, 1989.

FERNANDES, Florestan. A revolução burguesa no Brasil. Rio de Janeiro: Zahar, 1976.

FERNANDES, Florestan. Capitalismo dependente e classes sociais na América Latina. São Paulo: Global, 2009.

FERNANDES, Florestan. Sociedade de classes e subdesenvolvimento. Rio de Janeiro: Zahar, 1968.

FERRER, Walkiria Martinez Heinrich; ALVES, Giovanni. Flexibilização trabalhista e o empresariado brasileiro: alguns apontamentos.Prim@ facie, João Pessoa: PPGCJ, v.17, n. 35,2018

FILGUEIRAS, Vitor Araújo. As promessas da Reforma Trabalhista: combate ao desemprego e redução da informalidade. In: KREIN, José Dari; OLIVEIRA, Roberto Verás de; FILGUEIRAS, Vitor Araújo (org.). Reforma trabalhista no Brasil: promessas e realidade. Campinas: Curt Nimuendajú, 2019.

FIESP. FIESP e CIESP são contra redução obrigatória da jornada de trabalho. Portal FIESP, Notícias, São Paulo, $1^{\circ}$ fev. 2013. Disponível em: http://www.fiesp.com.br/noticias/fiesp-eciesp-sao-contra-reducao-obrigatoria-da-jornada-de-trabalho/. Acesso em: 31 jan. 2017. 


\section{tempordilis}

LARA, RICARDO; DIOGO, PABLO RAMON

FIESP. Livre para crescer: proposta para um Brasil moderno. São Paulo, 1990.

FIESP. Skaf elogia multiplicidade de pontos de vista do conselhão e defende reformas. Portal FIESP, Notícias, São Paulo: Federação das Indústrias do Estado de São Paulo FIESP, 21 nov. 2016. Disponível em: http://www.fiesp.com.br/noticias/skaf-elogiamultiplicidade-de-pontos-de-vista-do-conselhao-e-defende-reformas/. Acesso em: 31. Jan. 2017.

IBGE. Reforma trabalhista acentua o desemprego. Brasil 247, São Paulo, 30 maio 2019. Disponível em: https://www.brasil247.com/brasil/reforma-trabalhista-acentua-odesemprego-diz-pesquisadora?amp=1. Acesso em: 11. Abril. 2020.

INÁCIO, José Reginaldo; LARA, Ricardo (org.). Trabalho, Saúde e Direitos Sociais. Bauru: Canal 6, 2018.

KOWARICK, L. Trabalho e vadiagem: a origem do trabalho livre no Brasil. São Paulo: Editora 34, 2019.

KREIN, José Dari; OLIVEIRA, Roberto Verás de; FILGUEIRAS, Vitor Araújo (org.). Reforma Trabalhista no Brasil: promessas e realidade. Campinas: Curt Nimuendajú, 2019.

LARA, Ricardo. Modernização Trabalhista: um país “livre para crescer”. In: INÁCIO, José Reginaldo; LARA, Ricardo (org.). Trabalho, saúde e direitos sociais. Bauru: Canal 6, 2018.

LÊNIN, V. I. O Estado e a Revolução: A Doutrina do Marxismo sobre o Estado e as Tarefas do Proletariado na Revolução. São Paulo: Boitempo, 2017.

LUKÁCS, G. Para uma ontologia do ser social II. São Paulo: Boitempo, 2013.

MARINHO, Rogério. Modernização das leis trabalhistas: o Brasil pronto para o futuro. Petrópolis: De Petrus Editora, 2018.

MARX, Karl. Glosas críticas marginais ao artigo “o rei da Prússia e a reforma social”: de um prussiano. São Paulo: Expressão Popular, 2010.

MARX, Karl. O Capital: crítica da economia política. São Paulo: Boitempo, 2017.

MATTEI, Lauro; HEINEN, Vicente Loeblein. Impactos da Reforma Trabalhista no mercado de trabalho de Santa Catarina. In: ENCONTRO NACIONAL DA ABET, 16., Bahia. Anais [...]. Bahia: Universidade Federal da Bahia, 2019.

NETTO, José Paulo. Ditadura e serviço social: uma análise do serviço social no Brasil pós64. São Paulo: Cortez, 2015. 
NOSSO último grito de socorro: trabalhadores voltam a denunciar a Livraria Cultura. Passa Palavra, Noticiar, 19 fev. 2020. Disponível em:

https://passapalavra.info/2020/02/129948/. Acesso em: 12 abr. 2020.

\section{SILVA, Mauri Antonio. Consequências da crise do capital sobre a classe trabalhadora} brasileira (1990 a 2016). Tese (Doutorado em Serviço Social) - Universidade Federal de Santa Catarina, Florianópolis, 2017. p. 235-242.

SMARTLAB. Observatório de Segurança e Saúde no Trabalho: Promoção do meio ambiente do Trabalho Guiada por dados. [ferramenta de busca]. Disponível em: http://observatoriosst.mpt.mp.br/. Acesso em: 11 jul. 2020.

TONI, Graciliano. Conselho superior de relações do trabalho da FIESP tem como desafio modernizar o setor. Agência Indusnet Fiesp, São Paulo, 2 jul. 2015. Disponível em: http://www.fiesp.com.br/noticias/conselho-superior-de-relacoes-do-trabalho-da-fiesptem-como-desafio-modernizar-setor. Acesso em: 31 jan. 2017.

ZOCKUN, Maria Helena Garcia Pallares et al. Livre para crescer: proposta para um Brasil moderno. São Paulo: Cultura Editores Associados; Federação das Industrias do Estado de São Paulo, 1990.

\footnotetext{
Ricardo Lara Trabalhou concepção e delineamento; análise e interpretação dos dados; redação do artigo, revisão crítica e na aprovação da versão a ser publicada.

Doutor em Serviço Social pela Universidade Estadual Paulista. Pós-doutorado pelo Instituto de História Contemporânea da Universidade Nova de Lisboa. Pesquisador Bolsa Produtividade CNPq. Editor Chefe da Revista Katálysis. Membro do Conselho Editorial do Projeto Editorial Práxis. Coordenador do Núcleo de Estudos e Pesquisas: trabalho, "questão social" e América Latina (Brasil/NEPTQSAL). Pesquisador do Grupo de Estudos: capital, trabalho e educação (Brasil/GECATE); do Grupo de Investigação: História Global do Trabalho e dos Conflitos Sociais (Portugal/IHC/UNL) e do Observatório para as Condições de Trabalho e Vida (Portugal/OCTV). Coordenador de Pesquisa do Centro Socioeconômico (CSE/UFSC - 2017/2020).
}

Pablo Ramon Diogo Trabalhou na análise e interpretação dos dados.

Graduando em Serviço Social pela Universidade Federal de Santa Catarina - UFSC e integrante do Núcleo de Ensino e Pesquisa em Trabalho e Questão Social na América Latina - NEPTQSAL. Atualmente é bolsista PIBIC/CNPq do Projeto de Pesquisa 'A Ideologia da Modernização Trabalhista no Brasil' (2020-2021), como também participou como bolsista no mesmo projeto no ciclo 2019-2020. Já foi bolsista e voluntário do Projeto de Extensão do Núcleo de Estudos e Pesquisa sobre Profissões e Instituições (NEPPI) com o tema 'Uma Lição Desde o Fazer Profissional do Serviço Social: Enfrentamentos e Construções' (2018-2019). Como, também, já exerceu atividade de monitoria de ensino na disciplina 'Oficina Introdução à Vida Acadêmica' como bolsista (2018). 


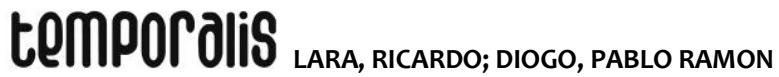

Temporalis, Brasília (DF), ano 20, n. 40, p. 165-181, jul./dez. 2020. | ISSN 2238-1856 